\title{
A drug safety evaluation of abiraterone acetate in the treatment of prostate cancer
}

\section{Pietro Castellan, Roberto Castellucci, Michele Marchioni, Cosimo De Nunzio, Giorgia Tema, Giulia Primiceri, Luigi Schips \& Luca Cindolo}

To cite this article: Pietro Castellan, Roberto Castellucci, Michele Marchioni, Cosimo De Nunzio, Giorgia Tema, Giulia Primiceri, Luigi Schips \& Luca Cindolo (2019): A drug safety evaluation of abiraterone acetate in the treatment of prostate cancer, Expert Opinion on Drug Safety, DOI: 10.1080/14740338.2019.1648428

To link to this article: https://doi.org/10.1080/14740338.2019.1648428

Accepted author version posted online: 29 Jul 2019.

Submit your article to this journal ๘

山 Article views: 29

View Crossmark data $₫$ 
Publisher: Taylor \& Francis \& Informa UK Limited, trading as Taylor \& Francis Group

Journal: Expert Opinion on Drug Safety

DOI: $10.1080 / 14740338.2019 .1648428$

A drug safety evaluation of abiraterone acetate in the treatment of prostate cancer

Pietro Castellan ${ }^{1}$, Roberto Castellucci ${ }^{1}$, Michele Marchioni ${ }^{2}$, Cosimo De Nunzio ${ }^{3}$, Giorgia Tema $^{3}$, Giulia Primiceri ${ }^{2}$, Luigi Schips ${ }^{1,2}$ and Luca Cindolo ${ }^{1}$

${ }^{1}$ Department of Urology, ASL02 Abruzzo, Chieti, Italy

2Department of Urology, University "G. d'Annunzio", Chieti, Italy

${ }^{3}$ Department of Urology, Sant'Andrea Hospital, University "La Sapienza”, Rome, Italy

\section{Corresponding author:}

Pietro Castellan

ASL02 Abruzzo - Urology Dept. - Via dei Vestini - 66100 Chieti - Italy

Tel.: +393408100333

Fax: +390871358253

Email : castellanpietro@gmail.com 


\begin{abstract}
Introduction: To evaluate the safety profile characteristics of abiraterone acetate (AA) in the treatment of metastatic prostate cancer ( $\mathrm{mPCa}$ ).

Areas covered: In this literature review the authors evaluate safety data from phase III trials investigating the combination of abiraterone acetate plus prednisone (AAP) in patients with metastatic prostate cancer. In particular, the aim was to clarify its toxicity profile, long-term exposure impact, and the correlation with general health-related quality of life (HRQoL).

Expert opinion: Based on the studies reviewed, it appears that abiraterone acetate has favourable outcomes, is effective and well tolerated, mostly in asymptomatic or slightly symptomatic patients, and has recognised toxicity profile characteristics. Incidence of adverse events (AEs), such as mineralocorticoid- and corticosteroid-releated AEs, and hepatotoxicity is well known and widely described. Understanding the toxicity profile of AA could assist decision-making in clinical practice.
\end{abstract}

Key words: abiraterone acetate, metastatic prostate cancer, androgen receptor, toxicity, castration-resistant prostate cancer, hormone-naïve prostate cancer 


\section{Drug summary box}

\begin{tabular}{|c|c|}
\hline Drug name & Abiraterone acetate \\
\hline Phase & Initial U.S. Approval: 2011 \\
\hline Indication & $\begin{array}{l}\text { - metastatic castration-resistant prostate cancer (CRPC) } \\
\text { - metastatic high-risk castration-sensitive prostate cancer (CSPC) }\end{array}$ \\
\hline $\begin{array}{l}\text { Pharmacology } \\
\text { description } \\
\text { Mechanism of action }\end{array}$ & $\begin{array}{l}\text { Cytochrome P450 17A1 inhibitor. } \\
\text { inhibition of CYP17 reduces androgen synthesis in the testes, the } \\
\text { adrenal glands, and the prostate, resulting in reduced serum } \\
\text { levels of testosterone and other androgens }\end{array}$ \\
\hline $\begin{array}{l}\text { Route of } \\
\text { administration }\end{array}$ & $\begin{array}{l}\text { 1,000 mg orally once daily with prednisone } 5 \mathrm{mg} \text { orally: } \\
\text { - twice daily for metastatic castration-resistant prostate cancer } \\
\text { (mCRPC) } \\
\text { - once daily for newly diagnosed, high-risk, metastatic, castration- } \\
\text { sensitive prostate cancer }\end{array}$ \\
\hline Chemical structure & \\
\hline Pivotal trials & COU-AA-301, COU-AA-302 \\
\hline
\end{tabular}




\section{Introduction}

Prostate cancer ( $\mathrm{PCa}$ ) is the second most common cancer in men and a leading cause of cancer-related deaths worldwide $(1,2)$. When the disease is diagnosed at the local or regional stages (3), external beam radiation therapy and surgery are the best options; however, after this initial treatment with curative intent, almost $34 \%$ of cancers will evolve into metastatic disease (4). Recent data suggest that about $5 \%$ of men are diagnosed with metastatic prostate cancer each year. Figures are increasing in the United States, with an incidence of PCa now $72 \%$ higher than in the last decade (5). Until 2014, advanced and metastatic prostate cancers were traditionally managed with androgen-deprivation therapy (ADT) (6). According to the literature, up to $80 \%$ of patients have a positive treatment response but progress to metastatic castration-resistant prostate cancer (mCRPC) is ultimately inevitable, with one third of patients developing resistance within one or two years (7). mCRPC is a clinically relevant phenotype with a high burden of mortality. Until 2010, it was usually managed with first-line, docetaxel-based chemotherapy (8). Recently, a large number of therapeutic options have emerged that show to increase survival and delay tumour progression when used before or after docetaxel (9). Key to these advances are a better understanding of androgen receptor (AR) pathways and the development of new target agents, most notably enzalutamide and abiraterone acetate $(10,11)$. Both of these drugs have received initial approval by the European Medicines Agency (EMA) and the United States Food and Drug Administration (FDA) for the treatment of mCRPC in both the pre- and post-docetaxel setting. Given their distinct mechanisms of action on AR signalling pathways, it is reasonable to expect that their toxicity profiles will also be different $(12,13)$; hence, several guideline treatments have been developed and $\mathrm{PCa}$ is now increasingly regarded as a chronic disease (14). Evidence from the literature suggests that these new hormonal agents improve survival in mPCa (15) and have a positive effect on patients' health-related quality of life (HRQOL); however, their toxicity profiles must be taken into account when selecting the most appropriate treatment (16).

The aim of this paper is to provide an overview of the safety profile of $A A$ in the treatment of metastatic prostate cancer.

\section{Body of review}

\subsection{Abiraterone acetate}


Abiraterone acetate (AA) is an irreversible selective inhibitor of CYP17A1, a member of the CYP/CYP450 family that converts pregnanes into steroid hormones, including androgen precursors (17). AA blocks the synthesis of androgenic steroids in the testes, in the adrenal gland, and in prostate tumour tissues. This causes systemic suppression of androgen signalling, which underlies progression to $\mathrm{mPCa}$ and development of mCRPC. The recommended dose for abiraterone acetate is $1000 \mathrm{mg} /$ dayly in combination with prednisone (the latter at a dose of $5 \mathrm{mg}$ twice daily for $\mathrm{mCRPC}$, and $5 \mathrm{mg}$ once daily for newly diagnosed, high-risk, metastatic, castration-sensitive prostate cancer).

\subsection{Mechanism of action}

Pharmacokinetic data for AA are available from a few phase I studies $(18,19)$. Absorption is strongly influenced by food intake and therefore AA is routinely administered under fasting conditions. The molecule is converted to its active metabolite in the intraluminal environment of the intestine (20) and in the liver, reaching its maximum concentration (Cmax) of 1.2-5 $\mu \mathrm{M}$ in approximately 1-2 h. Clearance is biphasic, with a terminal half-life of $5-16 \mathrm{~h}(18,19,21)$. The main metabolite excreted is $\mathrm{N}$-oxide abiraterone sulphate. There is significant intersubject variability in Cmax and drug exposure, with apparent clearance being lower in CRPC patients than in healthy subjects (22). AA has minimal effects on hepatic drug metabolism (CYP3A4), glucocorticoid biosynthesis (CYP11B1), and mineralocorticoid synthesis (CYP11B2) but is known to block the CYP17A1 enzyme (17a-hydroxylase/17,20-lyase). CYP17A1 is found in prostatic, testicular, and adrenal tissues, and its expression is 17 times higher in mCRPCs than in primary prostate tumours. It is located in the endoplasmic reticulum and plays a significant role in androgen synthesis and cortisol production (19, 23-26). AA is the active metabolite formed upon hydrolysis and irreversibly inhibits CYP17 (27-30). Inhibition of hydroxylase activity in turn suppresses pregnenolone and progesterone hydroxylation, limiting the subsequent conversion of hydroxylated metabolites to dehydroepiandrosterone and androstenedione, respectively. This causes decreased testosterone and DHT levels and ultimately leads to testosterone blockade in all tissues. As a result, synthesis of hormones such as cortisol is reduced. Cortisol precursors are the ultimate converted products of $17 \alpha$-hydroxypregnenolone and $17 \alpha$ hydroxyprogesterone (27). When all $17 \alpha$ hydroxylase activity is blocked, cortisol production is reduced and the negative feedback on adrenocorticotropic hormone (ACTH) secretion is affected. This leads to higher levels of ACTH production as found in the mineralocorticoid excess syndrome, which is 
characterised by hypertension, fluid retention, and hypokalaemia and has been found to be responsive to the synergistic effect of prednisone, dexamethasone, or corticosterone at low doses $(19,24-26,31-33)$.

\subsection{Clinical applications}

The effects of AA plus prednisone (AAP) in combination with ADT have been tested in large randomised clinical trials (RCTs). In the COU-AA-301 and COU-AA-302 registration trials, AA showed overall survival (OS) benefits both pre-and post-docetaxel $(34,35)$ and consequently became standard treatment for asymptomatic or mildly symptomatic docetaxel-naïve mCRCP patients with ECOG status $0-1$. In the COU-AA-301 study, the most common AEs were fatigue, back pain (30\%), nausea (30\%), constipation (26\%), and bone pain (25\%). Incidence of fluid retention and oedema was $31 \%$, while that of cardiac events (tachycardia and atrial fibrillation) was 13\%. In the COU-AA-302 trial, AEs (arthralgia, peripheral oedema, hot flushes, diarrhoea, hypokalaemia, and hypertension) occurred more frequently for AAP than placebo. AEs of grade 1 or 2 were mostly reported. These included grade 1-3 fatigue (40\%), fluid retention (29\%), hypertension (22\%), hypokalaemia $(17 \%)$, and increased levels of alanine aminotransferase (12\%) and aspartate aminotransferase (11\%) (36). Incidence of AErelated deaths was $4 \%$ in the AA group and 3\% in the placebo group. Notable benefits were prolonged OS and rPFS, delays in patient-reported pain progression and concurrent improvements in HRQoL parameters, including vitality, pain, general status, and urinary and sexual functioning. Median time to HRQoL deterioration was longer in patients in the AAP arm than in the placebo arm (12.7 months vs 8.3 months) (37). In this setting, AAP was an alternative to chemotherapy following progression to CRCP status. Building on the evidence in favour of AA, two recent RCTs investigated the efficacy and safety of AAP also in locally advanced and metastatic hormone-sensitive prostate cancer (mHSPC). One is the LATITUDE study (A Randomized, Double-blind, Comparative Study of Abiraterone Acetate Plus LowDose Prednisone Plus ADT Versus ADT Alone in Newly Diagnosed Subjects With High-Risk, Metastatic Hormone-naive Prostate Cancer [mHNPC] (38) and the other is the STAMPEDE

study, G arm, (Systemic Therapy in Advancing or Metastatic Prostate Cancer: Evaluation of Drug Efficacy) (39).

\subsection{1 $A A$ in $m C R P C$}

In the COU-AA-301 and -302 studies, AEs related to AA were predominantly grade 1 or 2; consequently, the rate of drug discontinuation or dose reduction was low $(9,40)$. There were 
no differences in all-grade toxicity with regard to nausea, constipation, bone pain, and arthralgia. Grade 3 (mostly fatigue, back pain, anaemia, and bone pain) and grade 4 adverse reactions occurred in less than $10 \%$ of patients (41).

In a recent study, Roviello et al demonstrated that CYP17 inhibitors significantly increase the risk of all-grade adverse events including hypokalaemia, hypertension, liver function test abnormalities, and cardiac events (RR ranging from 1.56 to 1.93). In particular, a major impact was observed in the incidence of all-grade liver function test abnormalities $(R R=1.93)$. CYP17 inhibition also increased the risk of grade $\geq 3$ cardiac disorders and hypokalaemia, and the incidence of all-grade and grade $\geq 3$ cardiac disorders and all-grade hypertension. Hypokalaemia was found to be a direct consequence of increased mineralocorticoid levels resulting from CYP17 inhibition. Although the condition might be particularly dangerous, monitoring (at least once a month) allows for a timely correction (42).

Another recent meta-analysis on the risk ratio $(R R)$ of cardiovascular events in mCRPC patients treated with hormonal agents pointed to an increased risk of all-grade cardiotoxicities $(R R=1.32)$ in the treatment group compared with placebo (43). Conversely, a study by Procopio et al showed no grade 3-4 adverse events in patients with pre-existing cardiac risk factors, including hypertension, cardiac ischaemia, arrhythmia, dyslipidaemia, and hyperglycaemia (44). In a real-life setting, Cindolo et al found relevant toxicity in 17 of 145 patients on AA therapy (12 with cardiovascular events and 5 with critical elevation of AST/ALT levels within 4 months) $(45,46)$. Fan et al assessed toxicity in chemotherapy-naïve mCRPC patients treated with $A A$, showing elevated alanine aminotransferase (ALT) (11.6\%), hypokalaemia (9.3\%), and hyperglycaemia (4.7\%) (47).

Zhu et al conducted a meta-analysis on the safety profile of abiraterone acetate that included 9,520 patients. Summary incidence of all-grade AEs was 99.09\% (95\% Cl: $98.70 \%-99.48 \%)$, RR of all-grade AEs was 1.01 (95\% Cl: 1.01-1.02, $\mathrm{P}<0.001)$, and incidence of high-grade AEs was $50.45 \%$ (95\% Cl: $48.40 \%-52.49 \%$ ). Discontinuation of therapy due to AEs was $12.81 \%$ (95\% Cl: $11.38 \%-14.24 \%)$ and incidence of fatal AEs was 5.42\% (95\% Cl: $1.79 \%-9.06 \%$ ). Generally, AA was associated with a significantly increased risk of ALT, AST, arthralgia, cardiac events, diarrhoea, oedema, hypertension, and hypokalaemia. Likewise, with regard to high-grade AEs, the risk of ALT, AST, cardiac events, hypertension, and urinary tract infections was significantly high (48). 
Two RCTs, the LATITUDE and STAMPEDE trials, investigated the safety and efficacy of AA in mHSPC patients $(38,39)$. In the LATITUDE trial, the rates of serious adverse events were similar in the ADT alone and AA groups. Adverse events resulting in dose modification or interruption were $17 \%$ in the ADT alone arm and $32 \%$ in the $A A$ arm. Treatment discontinuation rates were $10 \%$ in the ADT alone arm and $12 \%$ in the AA arm. In both the COU and LATITUDE trials, hypertension and hypokalaemia were more frequent in the $A A$ group, even taking into account methodological differences in the calculation of hypertension. Considering that hypertension was calculated with a different method when compared to COU-trial, anyway tighter with hypokalaemia were more frequent in the AA group. AA had better pain control (37\% risk reduction for worst pain progression) and pain interference progression (33\% risk reduction). AA also showed benefits in OS and rPFS and improvements in fatigue progression (35\% risk reduction) and fatigue interference progression ( $41 \%$ risk reduction). It also reduced the risk of HRQoL deterioration by $15 \%$. In the STAMPEDE trial, the percentage of grade $>3$ adverse events was similar in both arms (11\% in the ADT alone group and $15 \%$ in the AA group). Hypertension, respiratory disorders, and increased AST levels were also associated with AA.

These findings have led to the development of new guidelines for the management of mPCa $(49,50)$ recommending $\mathrm{AA}$ as a primary treatment. However, the search for new ARmodulating compounds is ongoing and no exisisting recommendation can be regarded as final or definitive.

\subsection{Safety evaluation}

Safety of AA has been tested in RCTs in different settings, such as pre-chemotherapy CRPC, post-chemotherapy CRPC, and metastatic, hormone-sensitive or high-risk locally advanced disease. The combination treatment of ADT with $A A$ and prednisone showed consistent safety results in each clinical trial (Table 1) (34). Interestingly, results were similar in the STAMPEDE and LATITUDE trials $(34,35)$ and also mirrored those of the COU-AA-301 and COU-AA-302 studies. In particular, the frequency of hypertension, oedema, and hypokalaemia in the STAMPEDE trial was comparable to or lower than in the other studies mentioned. In the LATITUDE trial, on the other hand, mineralocorticoid-mediated adverse events were slightly more frequent. The authors suggest that these differences could be due to the somewhat longer duration of AA treatment (35). 
Adverse events had similar rates in 3 out of 4 of the clinical trials examined and affected more than $90 \%$ of patients (up to $99 \%$ of patients in the COU-AA-302 and STAMPEDE trials) (34, 35, 39). High-grade (i.e. 3-5) adverse events were reported in approximately $50 \%$ of patients in the COU-AA-302 and STAMPEDE studies, and even higher rates were reported in the LATITUTE trial (Table 2). Conversely, the COU-AA-301 study consistently reported lower rates of overall and high-grade adverse events. Post-hoc analyses of the COU-AA-301 and COU-AA-302 studies provide evidence in support of the long-term safety of AAP. The overall incidence of corticosteroid-related AEs in the AAP and placebo groups was $25.5 \%$ and $23.3 \%$, respectively, with weight increase and hyperglycaemia being the most commonly reported. Incidence of $>3$ grade AEs was $5.1 \%$ in the AAP arm and $3.7 \%$ in the placebo arm (51).

In a recent randomised study, Attard et al evaluated the safety of AA with 4 glucocorticoid regimens and reported that combination with dexamethasone appears to be particularly active but may be associated with adverse metabolic consequences (52). However, it is of note that the corticosteroid-associated adverse events may be reduced with a different corticosteroid dosage and schedule. Fizazi et al explored the incidence of long-term corticosteroid-related adverse events in patients from the COU-AA-301 and COU-AA-302 studies (51). The main adverse events were hyperglicaemia and weight increase, which led the authors to conclude that low-dose corticosteroid treatment is safe and tolerable also in the long term (51). Using an alternative corticosteroid or switching from one corticosteroid to another may also be a way to prolong $A A$ efficacy. Fenioux et al tested the effects of switching from prednisone to dexamethasone at symptomatic PSA progression in MCRPC patients, achievinglonger progression-free survival and PSA decline without significant changes efficacy and tolerance (53).

The role of diet should also be considered. In a recent phase-two trial, 72 patients were allocated to either a low-fat or a standard diet. Patients in the low-fat arm showed a higher, albeit not statistically significant, number of events than those in the standard arm (32.4 vs. $17.6 \%)(54)$.

\subsection{Safety in special populations: elderly patients}

Use of AAP in the elderly warrants a thorough investigation of its potential side effects. A study by Smith et al showed that AAP has similar clinical benefits and tolerability in older and younger men and therefore qualifies as a valid choice for patients who may not tolerate other 
therapies with greater toxicity (55). Mineralocorticoid-related events were similar between the two groups and so were discontinuation rates. On the other hand, incidence of cardiac disorders and fluid retention was higher in older patients. Another ongoing clinical trial is investigating the incidence and severity of cognitive impairment in elderly men during treatment, focusing on quality of life, autonomy, and treatment compliance (56).

Another possible way to detect risks is to analyse safety data from spontaneous reporting systems. EudraVigilance is a system designed for collecting reports of suspected side effects. These reports are used to evaluate the benefits and risks of medicines during development and to monitor safety following authorisation in the European Economic Area (EEA). EudraVigilance has been in use since December 2001 (57). A retrospective analysis of population-based data from the EudraVigilance database showed that abiraterone acetate is well tolerated, with age having only a marginal effect on adverse events. Elderly patients, however, seem to be at higher risk of cardiac and metabolic disorders (Table 3 ).

As use of abiraterone acetate becomes more widespread, a higher number of adverse events are being reported in clinical trials, the only exception being a recently documented reduction in cardiac events (57). Similar considerations may also apply to other drugs used to treat prostate cancer, such as enzalutamide.

\subsection{Comparison with safety of other drugs}

In a recent network meta-analysis, Kassem et al. compared AA to the new standard of care in $\mathrm{mHSPC}$ treatment, docetaxel. The authors reported a relative risk of treatment-related mortality in the docetaxel + ADT and AA + ADT groups of 1.93 and 1.35, respectively, with no differences in mortality between the two arms. Differences were however found in grade 3-4 haematological adverse events (higher in the docetaxel group) and corticosteroid-related complications (higher in the AA group) (58). When comparing quality of life results in the same setting, Feyerabend et al. showed a slight benefit for AA over docetaxel (59). A recent long-term analysis of the STAMPEDE arm comparing AA and docetaxel showed similar rates of grade 3-5 adverse events (40 vs. $48 \%$ ) (60).

In chemotherapy-naïve mCRPC, current guidelines recommend other treatments (61). Among these, and similar to $\mathrm{AA}$, enzalutamide has a comparably favourable toxicity profile. It acts on the androgen axis and inhibits dihydrotestosterone binding to androgen receptors, androgen receptor translocation to the nucleus, and androgen receptor binding to DNA in the adrenal glands, the testes, andwithin the tumour microenvironment. The most frequently reported AEs 
are hot flushes and fatigue for enzalutamide, and hypokalaemia, fluid retention, and transaminase increase for AA. In a study by Hussein et al, AEs of special interest related to enzalutamide administration were hypertension (12\%), major adverse cardiovascular events $(5 \%)$, and mental impairment disorders (5\%). The most common AEs leading to death were cardiac events (1\%, nine patients) (62).

Recently, Moreira et al found that patients receiveing enzalutamide have a higher risk of allgrade fatigue but not all-grade or high-grade cardiovascular events, while AA is associated with all-grade and high-grade cardiovascular toxicity (63). In their meta-analysis, the authors concluded that $A A$ is safe even in patients with cardiac morbidity, although cardiotoxicity may well represent a life-threatening side effect. They also warned against underestimating enzalutamide-related fatigue, given that the latter is known to have a significant impact on patients' QoL, with repercussions on both their psychological status and self-care abilities.

Another meta-analysis by Zhu $\mathrm{J}$ et al compared the toxicity profiles of abiraterone acetate and enzalutamide and assessed the risk of associated adverse events (48). Results demonstrated that $A A$ increases the risk of all-grade and high-grade AEs. Most adverse events were secondary to elevated mineralocorticoid levels resulting from CYP17 blockade, with hypertension, hypokalaemia, cardiac events, and increased risk of liver test abnormalities being the most frequently reported. Conversely, enzalutamide was not associated with any significant increase of all-grade and high-grade adverse events, and its AE profile seemed mostly to include back pain, fatigue, hot flushes, and increased risk or hypertension. A few episodes of seizures were also reported, which were supposedly caused by acid-gated chloride channel inhibition.

One advantage of abiraterone acetate and enzalutamide over other therapies is their oral administration; however, their toxicity profile characteristics should be taken into consideration when selecting the most appropriate treatment.

\subsection{Conclusion}

In summary, treatment with AAP and ADT showed improved efficacy outcomes in terms of OS and rPFS, an acceptable safety profile, and consistent efficacy with a positive risk-benefit balance.

\section{Expert opinion}


In recent years, several mechanisms have been proposed to explain the progression to castration-resistant prostate cancer status. These include AR upregulation, induction of AR splice variants, AR point mutations, upregulation of glucocorticoid receptors, activation of alternative oncogenic signalling pathways, neuroendocrine transformations, and immune evasion through PD-L1 upregulation $(64,65)$. It seems thus reasonable to suggest that AR could be a viable therapeutic target in prostate cancer treatment (65). A better understanding of the way androgen receptor pathways work in prostate cancer has led to the development of new agents targeting the AR axis. These agents have shown to improve survival in mCRPC and more recently mHSPC patients. Treatement choices should be based on a balance of efficacy and safety and on detailed knowledge of the toxicity profile of each molecule under consideration.

In this review we provide an overview of the safety profile of $A A$ in the treatment of prostate cancer based on data from RCTs. We also refer to the most recent meta-analyses to better understand the actual incidence of AEs in clinical practice. All main guidelines specify which new hormonal agents are available in chemotherapy-naïve settings. More than $50 \%$ of $\mathrm{mPCa}$ patients never receive secondary treatment, mostly because of differences in management strategies across specialties, or knowledge of indications and contraindications, as well as existing comorbidities and patient ineligibility, presumably due to concerns about toxicity (66). The mPCa disease continuum, ranging as it does from patients with low-volume disease and low PSA levels to those with more rapidly progressive disease and high burden, is another variable worth considering. Usually, patients with symptomatic disease have the worst prognosis. Evidence from the STAMPEDE and LATITUDE trials suggests that early treatment in patients with high-risk and hormone-naïve MPC may enhance the therapeutic effects observed in mCRPC patients.

In this scenario, treatment decision-making should be enformed by a thorough understanding of a given drug profile. The most frequent adverse events of abiraterone acetate are known, particularly those related to mineralocorticoid excess, notably hypokalaemia, fluid retention, hypertension, and cardiac disorders, all largely preventable by the coadministration of lowdose glucocorticoids. Several strategies have been attempted to minimise the risk of serious cardiac AEs, including the addition of oral potassium or selective mineralocorticoid antagonists (67). In this respect, the identification of early predictive markers of AEs could help exclude patients at increased risk of cardiac toxicity during AA treatment. 
Abiraterone acetate has been the first no-chemo option in patients with metastatic hormone naïve PCa or mCRPC. Specifically, it has shown to have significant effects on overall survival with an acceptable profile, as observed after 4.5 years of treatment in the latest update of the LATITUDE trial (68).

The introduction of abiraterone and enzalutamide has completely changed the clinical management of patients with metastatic, castration-resistant PCA, since these agents increase overall survival without reducing the possible efficacy of subsequent chemotherapy. This opens a new era in CRPC management and will hopefully help identify new treatment paradigms. The availability of new therapies, in turn, makes it imperative to identify the optimum drug sequencing in the management of metastatic prostate cancer. Treatment choices ultimately depend on factors such as physician's preference and patient's health status. If a decision to start AAP is made, close monitoring for corticosteroid events is mandatory (69). Among possible complications, hyperglycaemia and diabetes must be given careful consideration. In particular, patients with non-insulin-dependent diabetes mellitus may become insulin-dependent when treated with AAP, and episodes of hyperglycaemia warrant dose adjustments if corticosteroid use is to be interrupted (70). Moreover, when prednisone is reduced or stopped, patients should be monitored for signs of adrenocortical insufficiency. On the other hand, data reported in the literature for a total treatment period of 4.5 years indicate similar serious adverse event rates and discontinuation rates for AAP and placebo.

Data on the ideal sequencing of anti-androgen therapies, both alone and in combination with other treatments, are also needed. Khalaf et al sought to address this issue in a clinical trial; however, they were ultimately unable to make any recommendations and simply pointed out that continuing with enzalutamide after an initial treatment with abiraterone could be an option, given that $34 \%$ of patients in their sample responded to such treatment (71).

The possibility to use $\mathrm{AA}$ as an adjuvant or neoadjuvant treatment in locally advanced disease is still a matter of debate and ongoing studies will hopefully clarify this aspect in the near future.

Further studies are ongoing to evaluate the possible role of $A A$ in association with chemotherapy, enzalutamide or apalutamide, an AR antagonist which has been recently released to manage patients with non-metastatic CRPC. In a few years, the availability of a generic drug may further increase use in clinical practice. Until now, treatment with AAP plus ADT has demonstrated to be effective and well tolerated, with a positive risk-benefit balance. 
It is anticipated that for the next 5 years AAP will remain one of the pillars of metastatic hormone-sensitive and castration-resistant PCA.

\section{Funding}

This paper was not funded.

\section{Declaration of interest}

The authors have no relevant affiliations or financial involvement with any organization or entity with a financial interest in or financial conflict with the subject matter or materials discussed in the manuscript. This includes employment, consultancies, honoraria, stock ownership or options, expert testimony, grants or patents received or pending, or royalties.

\section{Reviewer disclosures}

Peer reviewers on this manuscript have received grants, institutional research funding, personal fees, honoraria and travel support from Janssen, Astellas and Sanofi. Peer reviewers on this manuscript have no other relevant financial relationships or otherwise to disclose. 


\section{References}

Papers of special note have been highlighted as:

* of interest

${ }^{* *}$ of considerable interest

1. Jemal A, Siegel R, Xu J, et al. Cancer statistics, 2010. CA Cancer J Clin. 2010; 60: 277-300.

2. Malvezzi M, Bertuccio P, Levi F, et al. European cancer mortality predictions for the year 2013. Ann Oncol. 2013; 24: 792-800.

3. DeSantis CE, Lin CC, Mariotto AB, et al. Cancer treatment and survivorship statistics, 2014. CA Cancer J Clin. 2014; 64: 252-71.

4. Pound CR, Partin AW, Eisenberger MA, et al. Natural history of progression after PSA elevation following radical prostatectomy. JAMA. 1999; 281: 1591-7.

5. Weiner AB, Matulewicz RS, Eggener SE, et al. Increasing incidence of metastatic prostate cancer in the United States (2004-2013). Prostate Cancer Prostatic Dis. 2016; 19: 395-97.

6. Chen Y, Clegg NJ, Scher HI. Anti-androgens and androgen-depleting therapies in prostate cancer: new agents for an established target. The Lancet Oncology. 2009; 10: 981-91.

7. Pagliarulo V, Bracarda S, Eisenberger MA, et al. Contemporary role of androgen deprivation therapy for prostate cancer. Eur Urol. 2012; 61: 11-25.

8. Tannock IF, de Wit R, Berry WR, et al. Docetaxel plus prednisone or mitoxantrone plus prednisone for advanced prostate cancer. N Engl J Med. 2004; 351:1502-12.

9. Ryan CJ, Smith MR, de Bono JS, et al. Abiraterone in metastatic prostate cancer without previous chemotherapy. N Engl J Med. 2013; 368: 138-48.

10. Nakazawa M, Antonarakis ES, Luo J. Androgen receptor splice variants in the era of enzalutamide and abiraterone. Horm Cancer. 2014; 5: 265-73. 
11. de Bono JS, Oudard S, Ozguroglu M, et al. Prednisone plus cabazitaxel or mitoxantrone for metastatic castrationresistant prostate cancer progressing after docetaxel treatment: a randomised open-label trial. The Lancet. 2010; 376: 114754.

12. Rodriguez-Vida A, Galazi M, Rudman S, et al. Enzalutamide for the treatment of metastatic castration-resistant prostate cancer. Drug Des Devel Ther. 2015; 9: 3325-39.

13. Crawford ED, Shore ND, Petrylak DP, et al. Abiraterone acetate and prednisone in chemotherapy-naive prostate cancer patients: rationale, evidence and clinical utility. Ther Adv Med Oncol. 2017; 9: 319-33.

14. Bahl A, Masson S, Malik Z, et al. Final quality of life and safety data for patients with metastatic castration-resistant prostate cancer treated with cabazitaxel in the UK Early Access Programme (EAP) (NCT01254279). BJU International. 2015; 116: $880-87$.

15. Roviello G, Sigala S, Sandhu S, et al. Role of the novel generation of androgen receptor pathway targeted agents in the management of castration-resistant prostate cancer: A literature based meta-analysis of randomized trials. European Journal of Cancer. 2016; 61: 111-21.

16. van Andel G, Bottomley A, Fossa SD, et al. An international field study of the EORTC QLQ-PR25: a questionnaire for assessing the health-related quality of life of patients with prostate cancer. Eur J Cancer. 2008; 44: 2418-24.

17. Scott LJ. Abiraterone Acetate: A Review in Metastatic Castration-Resistant Prostrate Cancer. Drugs. 2017; 77 : 156576.

18. Attard G, Reid AH, Yap TA, et al. Phase I clinical trial of a selective inhibitor of CYP17, abiraterone acetate, confirms that castration-resistant prostate cancer commonly remains hormone driven. J Clin Oncol. 2008; 26: 4563-71.

19. Ryan CJ, Smith MR, Fong L, et al. Phase I clinical trial of the CYP17 inhibitor abiraterone acetate demonstrating clinical activity in patients with castration-resistant prostate cancer who received prior ketoconazole therapy. J Clin Oncol.

2010; 28: 1481-8. 
20. Stappaerts J, Geboers S, Snoeys J, et al. Rapid conversion of the ester prodrug abiraterone acetate results in intestinal supersaturation and enhanced absorption of abiraterone: in vitro, rat in situ and human in vivo studies. Eur $\mathrm{J}$ Pharm Biopharm. 2015; 90: 1-7.

21. Acharya M, Bernard A, Gonzalez M, et al. Open-label, phase I, pharmacokinetic studies of abiraterone acetate in healthy men. Cancer Chemother Pharmacol. 2012; 69: 1583-90.

22. Stuyckens K, Saad F, Xu XS, et al. Population pharmacokinetic analysis of abiraterone in chemotherapy-naive and docetaxel-treated patients with metastatic castration-resistant prostate cancer. Clin Pharmacokinet. 2014; 53: $1149-60$.

23. Chmelar R, Buchanan G, Need EF, et al. Androgen receptor coregulators and their involvement in the development and progression of prostate cancer. Int J Cancer. 2007; 120: 719-33.

24. Barrie SE, Potter GA, Goddard PM, et al. Pharmacology of novel steroidal inhibitors of cytochrome P450(17) alpha (17 alpha-hydroxylase/C17-20 lyase). J Steroid Biochem Mol Biol. 1994; 50: 267-73.

25. Katagiri M, Kagawa N, Waterman MR. The role of cytochrome b5 in the biosynthesis of androgens by human P450c17. Arch Biochem Biophys. 1995; 317: 343-7.

26. Dharia S, Slane A, Jian M, et al. Colocalization of P450c17 and cytochrome b5 in androgen-synthesizing tissues of the human. Biol Reprod. 2004; 71: 83-8.

27. Vasaitis TS, Bruno RD, Njar VC. CYP17 inhibitors for prostate cancer therapy. J Steroid Biochem Mol Biol. 2011; 125: 23-31.

28. Ryan CJ, Tindall DJ. Androgen receptor rediscovered: the new biology and targeting the androgen receptor therapeutically. J Clin Oncol. 2011; 29: 3651-8.

29. Yap TA, Carden CP, Attard G, et al. Targeting CYP17: established and novel approaches in prostate cancer. Curr Opin Pharmacol. 2008; 8: 449-57.

30. Zobniw CM, Causebrook A, Fong MK. Clinical use of abiraterone in the treatment of metastatic castration-resistant prostate cancer. Res Rep Urol. 2014; 6: 97-105. 
31. Sonpavde G, Attard G, Bellmunt J, et al. The role of abiraterone acetate in the management of prostate cancer: a critical analysis of the literature. Eur Urol. 2011; 60: 270-8.

32. Pinto-Bazurco Mendieta MA, Negri M, Jagusch C, et al. Synthesis, biological evaluation, and molecular modeling of abiraterone analogues: novel CYP17 inhibitors for the treatment of prostate cancer. J Med Chem. 2008; 51: 5009-18.

33. Li Z, Bishop AC, Alyamani M, et al. Conversion of abiraterone to D4A drives anti-tumour activity in prostate cancer. Nature. 2015; 523: 347-51.

34. Fizazi K, Scher HI, Molina A, et al. Abiraterone acetate for treatment of metastatic castration-resistant prostate cancer: final overall survival analysis of the COU-AA-301 randomised, double-blind, placebo-controlled phase 3 study. The Lancet Oncology. 2012; 13: 983-92.

35. Rathkopf DE, Smith MR, de Bono JS, et al. Updated interim efficacy analysis and long-term safety of abiraterone acetate in metastatic castration-resistant prostate cancer patients without prior chemotherapy (COU-AA-302). Eur Urol. 2014; 66: 815-25.

36. Ryan CJ, Smith MR, Fizazi K, et al. Abiraterone acetate plus prednisone versus placebo plus prednisone in chemotherapy-naive men with metastatic castration-resistant prostate cancer (COU-AA-302): final overall survival analysis of a randomised, double-blind, placebo-controlled phase 3 study. The Lancet Oncology. 2015; 16: 152-60.

37. Basch E, Autio K, Ryan CJ, et al. Abiraterone acetate plus prednisone versus prednisone alone in chemotherapynaive men with metastatic castration-resistant prostate cancer: patient-reported outcome results of a randomised phase 3 trial. The Lancet Oncology. 2013; 14: 1193-99.

38. Fizazi K, Tran N, Fein L, et al. Abiraterone plus Prednisone in Metastatic, Castration-Sensitive Prostate Cancer. N Engl J Med. 2017; 377: 352-60.

** Landmark trial that have changed the guidelines

39. James ND, de Bono JS, Spears MR, et al. Abiraterone for Prostate Cancer Not Previously Treated with Hormone Therapy. N Engl J Med. 2017; 377: 338-51. 
40. Fizazi K, Jones R, Oudard S, et al. Phase III, randomized, double-blind, multicenter trial comparing orteronel (TAK700) plus prednisone with placebo plus prednisone in patients with metastatic castration-resistant prostate cancer that has progressed during or after docetaxel-based therapy: ELM-PC 5. J Clin Oncol. 2015; 33: 723-31.

41. Saad F, Fizazi K, Jinga V, et al. Orteronel plus prednisone in patients with chemotherapy-naive metastatic castrationresistant prostate cancer (ELM-PC 4): a double-blind, multicentre, phase 3, randomised, placebo-controlled trial. The Lancet Oncology. 2015; 16: 338-48.

42. Roviello G, Sigala S, Danesi R, et al. Incidence and relative risk of adverse events of special interest in patients with castration resistant prostate cancer treated with CYP-17 inhibitors: A meta-analysis of published trials. Crit Rev Oncol Hematol. 2016; 101: 12-20.

43. lacovelli R, Verri E, Cossu Rocca M, et al. The incidence and relative risk of cardiovascular toxicity in patients treated with new hormonal agents for castration-resistant prostate cancer. Eur J Cancer. 2015; 51: 1970-7.

44. Procopio G, Grassi P, Testa I, et al. Safety of Abiraterone Acetate in Castration-resistant Prostate Cancer Patients With Concomitant Cardiovascular Risk Factors. Am J Clin Oncol. 2015; 38: 479-82.

45. Cindolo L, Natoli C, De Nunzio C, et al. Safety and efficacy of abiraterone acetate in chemotherapy-naive patients with metastatic castration-resistant prostate cancer: an Italian multicenter "real life" study. BMC Cancer. 2017; $17: 753$.

46. Marchioni M, Sountoulides $P$, Bada M, et al. Abiraterone in chemotherapy-naive patients with metastatic castrationresistant prostate cancer: a systematic review of 'real-life' studies. Ther Adv Urol. 2018; 10: 305-15.

47. Fan L, Dong B, Chi C, et al. Abiraterone acetate for chemotherapy-naive metastatic castration-resistant prostate cancer: a single-centre prospective study of efficacy, safety, and prognostic factors. BMC Urol. 2018; 18: 110.

48. Zhu J, Liao R, Su C, et al. Toxicity profile characteristics of novel androgen-deprivation therapy agents in patients with prostate cancer: a meta-analysis. Expert Rev Anticancer Ther. 2018; 18: 193-98.

* Meta-analysis about the toxicity profile characteristics of abiraterone acetate and enzalutamide

49. Castellan P, Marchioni M, Castellucci R, et al. Abiraterone acetate for early stage metastatic prostate cancer: patient selection and special considerations. Ther Clin Risk Manag. 2018; 14: 2341-47. 
50. Mottet N, Bellmunt J, Bolla M, et al. EAU-ESTRO-SIOG Guidelines on Prostate Cancer. Part 1: Screening, Diagnosis, and Local Treatment with Curative Intent. Eur Urol. 2017; 71: 618-29.

51. Fizazi K, Chi KN, de Bono JS, et al. Low Incidence of Corticosteroid-associated Adverse Events on Long-term Exposure to Low-dose Prednisone Given with Abiraterone Acetate to Patients with Metastatic Castration-resistant Prostate Cancer. Eur Urol. 2016; 70: 438-44.

52. Attard G, Merseburger AS, Arlt W, et al. Assessment of the Safety of Glucocorticoid Regimens in Combination With Abiraterone Acetate: A Randomized, Open-Label Phase 2 Study. JAMA Oncol. 2019.

** Abiraterone acetate in combination with dexamethasone appeared to be particularly active but may be associated with adverse metabolic consequences.

53. Fenioux C, Louvet C, Charton E, et al. Switch from abiraterone plus prednisone to abiraterone plus dexamethasone at asymptomatic PSA progression in patients with metastatic castration-resistant prostate cancer. BJU Int. 2019; 123: 300-06.

54. Szmulewitz RZ, Peer CJ, Ibraheem A, et al. Prospective International Randomized Phase II Study of Low-Dose Abiraterone With Food Versus Standard Dose Abiraterone In Castration-Resistant Prostate Cancer. J Clin Oncol. 2018; 36: 1389-95.

55. Smith MR, Rathkopf DE, Mulders PF, et al. Efficacy and Safety of Abiraterone Acetate in Elderly (75 Years or Older) Chemotherapy Naive Patients with Metastatic Castration Resistant Prostate Cancer. J Urol. 2015; 194: $1277-84$.

56. Lange $\mathrm{M}$, Laviec $\mathrm{H}$, Castel $\mathrm{H}$, et al. Impact of new generation hormone-therapy on cognitive function in elderly patients treated for a metastatic prostate cancer: Cog-Pro trial protocol. BMC Cancer. 2017; 17: 549.

57. EudraVigilance.

http://www.ema.europa.eu/ema/index.jsp?curl=pages/regulation/general/general content 000679.jsp\&mid=WC0b01ac0580 0250b5. Accessed 20 Oct 2018.

** a possible way to detect risks and to analyse safety data from spontaneous reporting systems 
58. Kassem L, Shohdy KS, Abdel-Rahman O. Abiraterone acetate/androgen deprivation therapy combination versus docetaxel/androgen deprivation therapy combination in advanced hormone-sensitive prostate cancer: a network metaanalysis on safety and efficacy. Curr Med Res Opin. 2018; 34: 903-10.

** Patients with metastatic HSPC (mHSPC) who received abiraterone acetate with ADT had better PFS and less toxicity compared to those receiving docetaxel with ADT

59. Feyerabend S, Saad F, Li T, et al. Survival benefit, disease progression and quality-of-life outcomes of abiraterone acetate plus prednisone versus docetaxel in metastatic hormone-sensitive prostate cancer: A network meta-analysis. Eur $\mathrm{J}$ Cancer. 2018; 103: 78-87.

60. Sydes MR, Spears MR, Mason MD, et al. Adding abiraterone or docetaxel to long-term hormone therapy for prostate cancer: directly randomised data from the STAMPEDE multi-arm, multi-stage platform protocol. Ann Oncol. 2018; 29: 123548.

61. Bandini M, Pompe RS, Marchioni M, et al. Improved cancer-specific free survival and overall free survival in contemporary metastatic prostate cancer patients: a population-based study. Int Urol Nephrol. 2018; 50: 71-78.

62. Hussain M, Fizazi K, Saad F, et al. Enzalutamide in Men with Nonmetastatic, Castration-Resistant Prostate Cancer. N Engl J Med. 2018; 378: 2465-74.

63. Moreira RB, Debiasi M, Francini E, et al. Differential side effects profile in patients with mCRPC treated with abiraterone or enzalutamide: a meta-analysis of randomized controlled trials. Oncotarget. 2017; 8: 84572-78.

64. Boudadi K, Antonarakis ES. Resistance to Novel Antiandrogen Therapies in Metastatic Castration-Resistant Prostate Cancer. Clin Med Insights Oncol. 2016; 10: 1-9.

65. Chandrasekar T, Yang JC, Gao AC, et al. Targeting molecular resistance in castration-resistant prostate cancer. BMC Med. 2015; 13: 206.

66. Engel-Nitz NM, Alemayehu B, Parry D, et al. Differences in treatment patterns among patients with castration-resistant prostate cancer treated by oncologists versus urologists in a US managed care population. Cancer Manag Res. 2011; 3: 233-45. 
67. Attard G, Reid AH, Auchus RJ, et al. Clinical and biochemical consequences of CYP17A1 inhibition with abiraterone given with and without exogenous glucocorticoids in castrate men with advanced prostate cancer. J Clin Endocrinol Metab. 2012; 97: 507-16.

68. ASCO Update.

https://http://www.urotoday.com/conference-highlights/asco-gu-2019/asco-gu-2019-prostate-cancer/110261-asco-gu-2019final-analysis-of-latitude-a-phase-iii-in-patients-with-newly-diagnosed-high-risk-metastatic-castration-naive-prostate-cancertreated-with-abiraterone-acetate-prednisone-added-to-adt.html Accessed 20 Mar 2019.

69. Auchus RJ, Yu MK, Nguyen S, et al. Use of prednisone with abiraterone acetate in metastatic castration-resistant prostate cancer. Oncologist. 2014; 19: 1231-40.

70. Dorff TB, Crawford ED. Management and challenges of corticosteroid therapy in men with metastatic castrateresistant prostate cancer. Ann Oncol. 2013; 24: 31-8.

71. Khalaf D. A Randomized Phase II Study of Sequencing Abiraterone Acetate and Enzalutamide in Metastatic Castration-Resistant Prostate Cancer. ASCO. 2018. 


\section{Tables}

Table 1 - Adverse events of abiraterone acetate in phase III clinical trials. Events reported for all grades as frequencies (\%) in the treatment arm.

Table 2 - Grade 3 to 5 adverse events of abiraterone acetate in phase III clinical trials. Events reported for all grades as frequencies (\%) in the treatment arm.

Table 3: Age influence on adverse events in patients treated with AAP and ENZ (Eudra Vigilance 20 October 2018). 
Table 1 - Adverse events of abiraterone acetate in phase III clinical trials. Events reported for all grades as frequencies (\%) in the treatment arm.

\begin{tabular}{|c|c|c|c|c|}
\hline & $\begin{array}{l}\text { Post-chemothearpy } \\
\text { CRPC }\end{array}$ & $\begin{array}{c}\text { Pre-chemotherapy } \\
\text { CRPC }\end{array}$ & \multicolumn{2}{|c|}{ Hormone-sensitive prostate cancere } \\
\hline Adverse event type & COU-AA-301 & COU-AA-302 & STAMPEDE & LATITUDE \\
\hline Anaemia & $198(25)$ & & $+\sqrt{2}=$ & $54(9)$ \\
\hline Thrombocytopoenia & $30(4)$ & & +8 & \\
\hline Neutropoenia & $8(1)$ & & $\nabla$ & \\
\hline Febrile neutropoenia & $3(<1)$ & & & \\
\hline Diarrhoea & $156(20 \%)$ & $127(23)$ & & \\
\hline Fatigue & $372(47)$ & $215(40)$ & $21(2)$ & $77(13)$ \\
\hline Asthenia & $122(15)$ & & & \\
\hline Back pain & $262(33)$ & $180(33)$ & & $10(18)$ \\
\hline Nausea & $258(33)$ & $130(24)$ & & \\
\hline Vomiting & $11(24)$ & & & \\
\hline Haematuria & $73(9)$ & 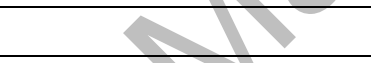 & & \\
\hline Abdominal pain & $102(13)$ & & & \\
\hline Limb pain & $156(20)$ & $93(17)$ & & \\
\hline Dyspnoea & $116(15)$ & Pr & & \\
\hline Constipation & $223(28)$ & $128(24)$ & & \\
\hline Pyrexia & $80(10)$ & & & \\
\hline Arthralgia & $239(30)$ & $159(29)$ & & \\
\hline Urinary tract infection & $105(13)$ & & & \\
\hline Pain (Muskoskeletal pain) & $38(5)$ & $88(16)$ & $68(7)^{* *}$ & \\
\hline Bone pain & $216(27)$ & $113(21)$ & & $74(12)$ \\
\hline Fluid retention (oedema) & $261(33)$ & 159 (29) & $5(1)$ & \\
\hline Hypokalaemia & $143(18)$ & $93(17)$ & $12(1)$ & $122(20)$ \\
\hline Cardiac disorders & $126(16)$ & $110(20)$ & $24(2)$ & $74(12)$ \\
\hline Liver test abnormalities & $89(11)$ & $125(33)$ & $70(7)$ & $185(31)$ \\
\hline Hypertension & $88(11)$ & $118(22)$ & $44(5)$ & $219(37)$ \\
\hline Hot flushes & & $123(23)$ & $129(14)^{*}$ & \\
\hline Cough & & $98(18)$ & & \\
\hline
\end{tabular}

*Included as endocrine disorders with impotence; ${ }^{* *}$ Muskoskeletal disorders 


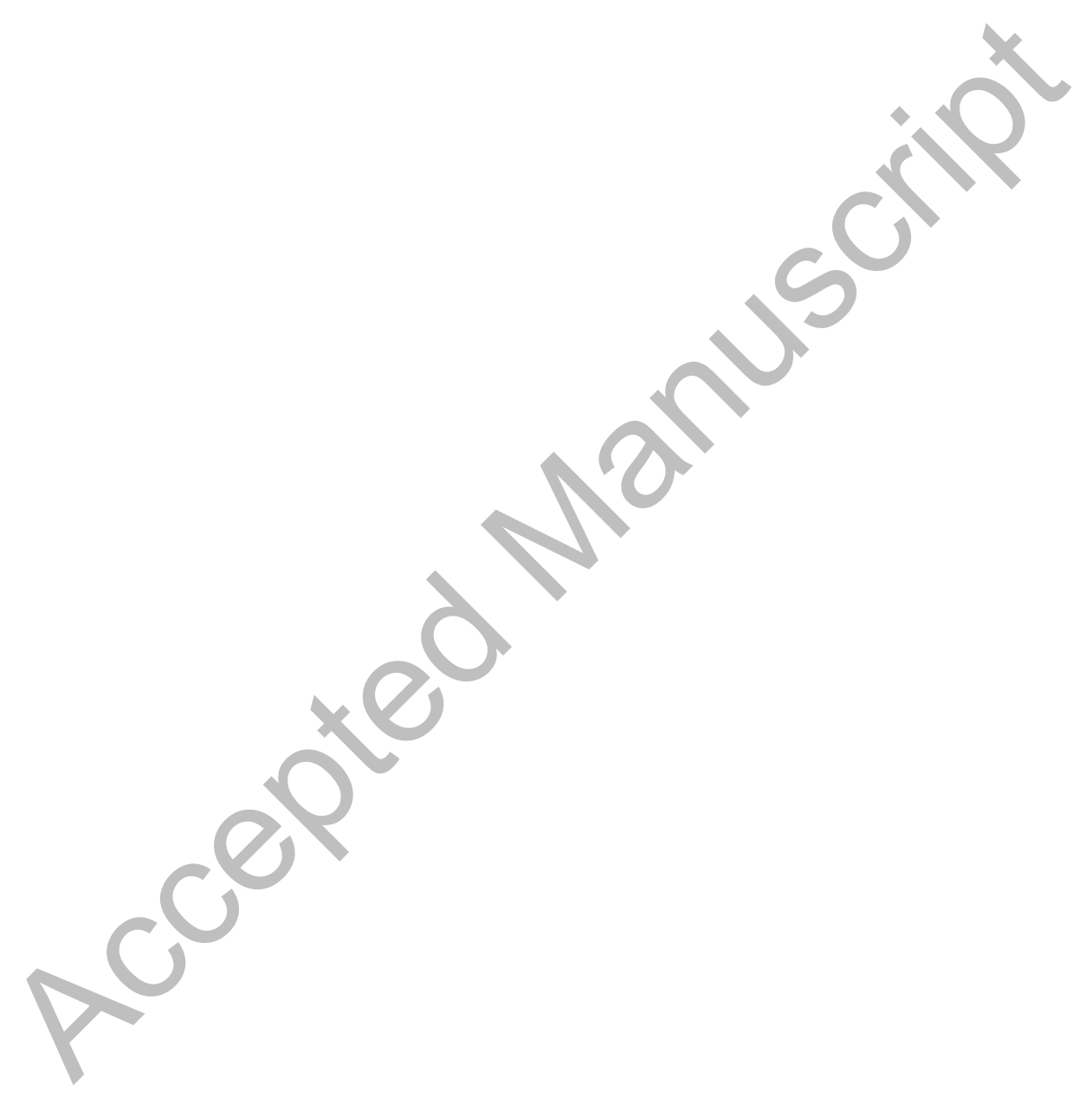


Table 2 - Grade 3 to 5 adverse events of abiraterone acetate in phase III clinical trials. Events reported for all grades as frequencies (\%) in the treatment arm.

\begin{tabular}{|c|c|c|c|c|}
\hline & Post-chemothearpy CRPC & Pre-chemotherapy CRPC & \multicolumn{2}{|c|}{ Hormone-sensitive prostate cancere } \\
\hline Adverse event type & COU-AA-301 & COU-AA-302 & STAMPEDE & LATITUDE \\
\hline Total & $610(77)$ & $538(99)$ & $943(99)$ & $558(93)$ \\
\hline Grade 3-5 & $182(24)$ & $267(49)$ & $443(47)$ & $374(63)$ \\
\hline
\end{tabular}


Table 3: Age influence on adverse events in patients treated with AAP and ENZ (Eudra Vigilance 20 October 2018). PRR1: [6585] vs <65; PRR2: $>85 \mathrm{vs}<65$. *statistically significant $p<0,05$, PRR: pooled relative risk.

\begin{tabular}{|c|c|c|c|c|c|c|c|c|c|c|}
\hline & \multicolumn{5}{|c|}{ ABIRATERONE } & \multicolumn{5}{|c|}{ ENZALUTAMIDE } \\
\hline Age & $<65$ & [65-85] & $>85$ & PRR1 & PRR 2 & $<65$ & [65-85] & $>85$ & PRR1 & PRR 2 \\
\hline Total Adverse Events & 1090 & 6299 & 1613 & & & 4170 & 24134 & 7417 & & \\
\hline $\begin{array}{l}\text { Blood and lymphatic } \\
\text { system disorders }\end{array}$ & 29 & 180 & 36 & $\begin{array}{c}1,07 \\
(0,72-1,58) \\
\end{array}$ & $\begin{array}{c}0,83 \\
(0,51-1,35) \\
\end{array}$ & 64 & 255 & 61 & $\begin{array}{c}0,69 \\
(0,52-0,90)^{*}\end{array}$ & $\begin{array}{c}0,54 \\
(0,37-0,76)^{*}\end{array}$ \\
\hline $\begin{array}{c}\text { Cardiac disorder (Atrial } \\
\text { Fibrillation) }\end{array}$ & 39 & 335 & 94 & $\begin{array}{c}1,48 \\
(1,07-2,05)^{*}\end{array}$ & $\begin{array}{c}1,62 \\
(1,12- \\
2,32)^{*}\end{array}$ & 47 & 463 & 201 & $\begin{array}{c}1,70 \\
(1,26-2,29)^{*}\end{array}$ & $\begin{array}{c}2,40 \\
(1,75-3,29)^{*}\end{array}$ \\
\hline $\begin{array}{l}\text { Ear and labyrinth } \\
\text { disorders }\end{array}$ & 3 & 16 & 4 & $\begin{array}{c}0,92 \\
(0,26-3,16)\end{array}$ & $\begin{array}{c}0,90 \\
(0,20-3,97)\end{array}$ & 12 & 128 & 35 & $\begin{array}{c}1,84 \\
(1,02-3,32)\end{array}$ & $\begin{array}{c}1,64 \\
(0,85-3,15)\end{array}$ \\
\hline Endocrine disorders & 3 & 46 & 10 & $\begin{array}{c}2,65 \\
(0,83-8,52) \\
\end{array}$ & $\begin{array}{c}2,23 \\
(0,61-8,07) \\
\end{array}$ & 5 & 16 & 11 & $\begin{array}{c}0,55 \\
(0,20-1,51) \\
\end{array}$ & $\begin{array}{c}1,23 \\
(0,43-3,55) \\
\end{array}$ \\
\hline Eye disorders & 14 & 47 & 9 & $\begin{array}{c}1,59 \\
(0,88-2,87)\end{array}$ & $\begin{array}{c}0,43 \\
(0,18- \\
0,98)^{*}\end{array}$ & 27 & 268 & 61 & $\begin{array}{c}1,71 \\
(1,15-2,54)^{*}\end{array}$ & $\begin{array}{c}1,27 \\
(0,80-1,99)\end{array}$ \\
\hline $\begin{array}{c}\text { Gastrointestinal } \\
\text { disorders (Abdominal } \\
\text { pain, nausea, } \\
\text { Constipation, Diarrea) }\end{array}$ & 74 & 357 & 99 & $\begin{array}{c}0,83 \\
(0,66-1,06)\end{array}$ & $\begin{array}{c}0,89 \\
(0,66-1,19)\end{array}$ & 224 & 1880 & 306 & $\begin{array}{c}1,45 \\
(1,26-1,66)^{*}\end{array}$ & $\begin{array}{c}0,76 \\
(0,65-0,90)^{*}\end{array}$ \\
\hline $\begin{array}{l}\text { General disorders and } \\
\text { administration site } \\
\text { conditions (astenia, } \\
\text { fatigue pain...) }\end{array}$ & 187 & 1125 & 345 & $\begin{array}{c}1,04 \\
(0,90-1,19)\end{array}$ & $\begin{array}{l}1,23 \\
(1,05- \\
1,45)^{*}\end{array}$ & 1080 & 5861 & 2118 & $\begin{array}{c}0,94 \\
(0,89-0,99)^{*}\end{array}$ & $\begin{array}{c}1,10 \\
(1,03-1,17)^{*}\end{array}$ \\
\hline Hepatobiliary disorders & 52 & 260 & 37 & $\begin{array}{c}0,87 \\
(0,64-1,15)\end{array}$ & $\begin{array}{c}0,48 \\
(0,31- \\
0,72)^{*}\end{array}$ & 25 & 118 & 24 & $\begin{array}{c}0,82 \\
(0,53-1,25)\end{array}$ & $\begin{array}{c}0,54 \\
(0,31-0,94)^{*}\end{array}$ \\
\hline $\begin{array}{l}\text { Immune system } \\
\text { disorders }\end{array}$ & 0 & 7 & 5 & & & 12 & 52 & 15 & $\begin{array}{c}0,74 \\
(0,40-1,40)\end{array}$ & $\begin{array}{c}0,70 \\
(0,32-1,50)\end{array}$ \\
\hline
\end{tabular}




\begin{tabular}{|c|c|c|c|c|c|c|c|c|c|c|}
\hline $\begin{array}{l}\text { Infections and } \\
\text { infestations }\end{array}$ & 44 & 337 & 113 & $\begin{array}{c}1,32 \\
(0,97-1,80)\end{array}$ & $\begin{array}{r}1,72 \\
(1,22- \\
2,41)^{*}\end{array}$ & 105 & 915 & 322 & $\begin{array}{c}1,50 \\
(1,23-1,84)^{*}\end{array}$ & $\begin{array}{c}1,72 \\
(1,38- \\
2,14)^{*}\end{array}$ \\
\hline $\begin{array}{l}\text { Injury, poisoning and } \\
\text { procedural } \\
\text { complications }\end{array}$ & 47 & 374 & 118 & $\begin{array}{c}1,37 \\
(1,02-1,85)\end{array}$ & $\begin{array}{c}1,68 \\
(1,20- \\
2,33)^{*}\end{array}$ & 264 & 1570 & 683 & $\begin{array}{c}1,02 \\
(0,91-1,16)\end{array}$ & $\begin{array}{c}1,45 \\
(1,26-1,67)^{*}\end{array}$ \\
\hline Investigations & 125 & 667 & 149 & $\begin{array}{c}0,92 \\
(0,77-1,10)\end{array}$ & $\begin{array}{c}0,80 \\
(0,63- \\
0,99)^{*}\end{array}$ & 300 & 1712 & 446 & $\begin{array}{c}0,98 \\
(0,87-1,11)\end{array}$ & $\begin{array}{c}0,83 \\
(0,72-0,96)^{*}\end{array}$ \\
\hline $\begin{array}{c}\text { Metabolism and } \\
\text { nutrition disorders } \\
\text { (descreased apetite, } \\
\text { fluid retention) }\end{array}$ & 48 & 381 & 104 & $\begin{array}{c}1,37 \\
(1,02-1,84)^{*}\end{array}$ & $\begin{array}{r}1,45 \\
(1,03- \\
2,02)^{*}\end{array}$ & 117 & 1006 & 345 & $\begin{array}{c}1,48 \\
(1,23-1,79)^{*}\end{array}$ & $\begin{array}{c}1,65 \\
(1,35-2,03)\end{array}$ \\
\hline $\begin{array}{l}\text { Musculoskeletal and } \\
\text { connective tissue } \\
\text { disorders (back pain, } \\
\text { arthralgia, bone pain) }\end{array}$ & 52 & 218 & 41 & $\begin{array}{c}0,72 \\
(0,53-0,97)^{*}\end{array}$ & $\begin{array}{c}0,53 \\
(0,35- \\
0,79)^{*}\end{array}$ & 250 & 1228 & 297 & $\begin{array}{c}0,84 \\
(0,74-0,96)^{*}\end{array}$ & $\begin{array}{c}0,66 \\
(0,56-0,78)^{*}\end{array}$ \\
\hline $\begin{array}{l}\text { Neoplasms benign, } \\
\text { malignant and } \\
\text { unspecified (incl cysts } \\
\text { and polyp }\end{array}$ & 130 & 563 & 110 & $\begin{array}{c}0,74 \\
(0,62-0,89)\end{array}$ & $\begin{array}{c}0,57 \\
(0,44- \\
0,72)^{*}\end{array}$ & 616 & 2588 & 713 & $\begin{array}{c}0,72 \\
(0,67-0,78)^{*}\end{array}$ & $\begin{array}{c}0,65 \\
(0,58-0,72)^{*}\end{array}$ \\
\hline $\begin{array}{c}\text { Nervous system } \\
\text { disorders (headache) }\end{array}$ & 59 & 302 & 81 & $\begin{array}{c}0,89 \\
(0,67-1,16) \\
\end{array}$ & $\begin{array}{c}0,92 \\
(0,66-1,27) \\
\end{array}$ & 318 & 2023 & 627 & $\begin{array}{c}1,09 \\
(0,98-1,23)\end{array}$ & $\begin{array}{c}1,10 \\
(0,97-1,26) \\
\end{array}$ \\
\hline Psychiatric disorders & 24 & 85 & 39 & $\begin{array}{c}0,61 \\
(0,39-0,95)\end{array}$ & $\begin{array}{c}1,09 \\
(0,66- \\
1,80) \\
\end{array}$ & 145 & 761 & 219 & $\begin{array}{c}0,90 \\
(0,76-1,07)\end{array}$ & $\begin{array}{c}0,85 \\
(0,69-1,04)\end{array}$ \\
\hline $\begin{array}{l}\text { Renal and urinary } \\
\text { disorders }\end{array}$ & 31 & 226 & 47 & $\begin{array}{c}1,26 \\
(0,87-1,82)\end{array}$ & $\begin{array}{c}1,01 \\
(0,65- \\
1,58)\end{array}$ & 75 & 476 & 145 & $\begin{array}{c}1,09 \\
(0,86-1,39)\end{array}$ & $\begin{array}{c}1,08 \\
(0,82-1,43)\end{array}$ \\
\hline $\begin{array}{l}\text { Reproductive system } \\
\text { and breast disorders }\end{array}$ & 5 & 19 & 5 & $\begin{array}{c}0,65 \\
(0,24-1,76)\end{array}$ & $\begin{array}{c}0,67 \\
(0,19-2,30)\end{array}$ & 21 & 81 & 18 & $\begin{array}{c}0,66 \\
(0,41-1,07)\end{array}$ & $\begin{array}{c}0,48 \\
(0,25-0,90)^{*} \\
\end{array}$ \\
\hline $\begin{array}{l}\text { Respiratory, thoracic } \\
\text { and mediastinal }\end{array}$ & 35 & 250 & 75 & $\begin{array}{c}1,23 \\
(0,87-1,75)\end{array}$ & $\begin{array}{c}1,43 \\
(0,97-2,12)\end{array}$ & 91 & 764 & 285 & $\begin{array}{c}1,45 \\
(1,17-1,79)^{*} \\
\end{array}$ & $\begin{array}{c}1,76 \\
(1,39-2,22)^{*}\end{array}$ \\
\hline
\end{tabular}




\begin{tabular}{|c|c|c|c|c|c|c|c|c|c|c|}
\hline disorders & & & & & & & & & & \\
\hline $\begin{array}{l}\text { Skin and subcutaneous } \\
\text { tissue disorders }\end{array}$ & 24 & 125 & 22 & $\begin{array}{c}0,90 \\
(0,59-1,40)\end{array}$ & $\begin{array}{c}0,61 \\
(0,34-1,08) \\
\end{array}$ & 98 & 556 & 125 & $\begin{array}{c}0,98 \\
(0,79-1,21)\end{array}$ & $\begin{array}{c}0,71 \\
(0,55-0,93)^{*}\end{array}$ \\
\hline $\begin{array}{l}\text { Social circumstances } \\
\text { (Disability, walking aid) }\end{array}$ & 2 & 8 & 4 & $\begin{array}{c}0,69 \\
(0,14-3,26)\end{array}$ & $\begin{array}{c}1,34 \\
(0,25-7,28)\end{array}$ & 17 & 66 & 34 & $\begin{array}{c}0,67 \\
(0,39-1,14)\end{array}$ & $\begin{array}{c}1,12 \\
(0,63-2,01)\end{array}$ \\
\hline $\begin{array}{c}\text { Surgical and medical } \\
\text { procedures }\end{array}$ & 28 & 164 & 34 & $\begin{array}{c}1,01 \\
(0,68-1,50)\end{array}$ & $\begin{array}{c}0,81 \\
(0,49-1,33) \\
\end{array}$ & 123 & 613 & 153 & $\begin{array}{c}0,86 \\
(0,71-1,04) \\
\end{array}$ & $\begin{array}{c}0,70 \\
(0,55-0,88)^{*}\end{array}$ \\
\hline $\begin{array}{c}\text { Vascular } \\
\text { disorders(hypertension, } \\
\text { flushing) }\end{array}$ & 34 & 205 & 50 & $\begin{array}{c}1,04 \\
(0,73-1,49)\end{array}$ & $\begin{array}{c}0,98 \\
(0,64-1,50)\end{array}$ & 134 & 734 & 173 & $\begin{array}{c}0,94 \\
(0,79-1,13)\end{array}$ & $\begin{array}{c}0,72 \\
(0,58-0,90)^{*}\end{array}$ \\
\hline
\end{tabular}

